IJBPAS, September, 2020, 9(9): 2212-2230

ISSN: 2277-4998

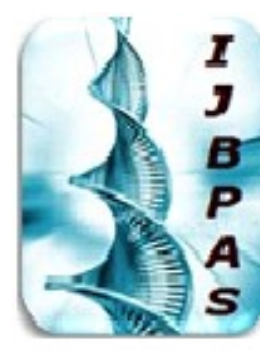

International Journal of Bhology, Pharmacy

and Allied Sciences (IJBPAS)

'A Bridgs Between Caboratory and Qendo'

Www.ijbpas,com

\title{
STUDIES ON THE SUSCEPTIBILITY OF COMMON UROPATHOGENS TO TOILET SEAT SANITIZERS AND THEIR ANTIBIOGRAM
}

\section{ROY $\mathrm{S}^{1^{*}}$, DATTA $\mathrm{A}^{2}$, GHOSH $\mathrm{A}^{2}$, MANDAL $\mathrm{G}^{2}$, BANERJEE $\mathrm{S}^{2}$ AND ROY $\mathrm{L}^{3}$}

1: Assistant Professor, Post-Graduate Department of Biotechnology, St. Xavier's College (Autonomous), 30, Mother Teresa Sarani, Kolkata-700 016, West Bengal, India

2: $4^{\text {th }}$ Year M.Sc. (5 Year Integrated) students, Post-Graduate Department of Biotechnology, St. Xavier's College (Autonomous), 30, Mother Teresa Sarani, Kolkata-700 016, West Bengal, India

3: State-Aided College Teacher, Department of Microbiology, Sarsuna College (under University of

Calcutta), 4/HB/A, Ho-Ch-Minh Sarani, Sarsuna Upanagari, Kolkata-700 061, West Bengal, India

*Corresponding Author: Souvik Roy: E-Mail: souvikroybiotech@sxccal.edu; Tel.: +91 9831316389

Received 23 ${ }^{\text {rd }}$ Jan. 2020; Revised $25^{\text {th }}$ Feb. 2020; Accepted $30^{\text {th }}$ March 2020; Available online $1^{\text {st }}$ Sept. 2020

https://doi.org/10.31032/IJBPAS/2020/9.9.5178

\begin{abstract}
Background: Unhygienic public washrooms are potential reservoirs of urinary tract infection (UTI)causing pathogens. Recently, there is a surge of non-medical grade toilet seat sanitizers that claim to protect against UTIs. This work, a first of its kind, was done keeping in mind public health interests, as UTI is very common among women and children. Objective: To study the susceptibility of common uropathogens to toilet seat sanitizers, and determination of their antibiogram. Materials and methods: Toilet seat washes from ladies' public washrooms of a major railway terminal station, a tertiary care hospital, and a shopping mall were collected before and after spraying sanitizers. Each wash was cultured on nutrient agar for total heterotrophic count (THC), followed by cultivation on selective media to confirm the presence of the common uropathogens by standard microbiological and biochemical procedures. A comparative contamination analysis was made, and respective efficacies of sanitizers determined. The susceptibilities of the uropathogen isolates to some common and some lesser-used antibiotics was also studied. Results and Discussion: There was a significant reduction in THC on applying the toilet seat sanitizers, from which the relative efficacies of the sprays tested was calculated and compared. Several notorious uropathogens of public health concern were isolated from the toilet seat washes, among which E. coli showed multi-drug resistance towards three common antibiotics.
\end{abstract}


Conclusion: This makes this novel study clinically significant, showing the prevalence of antibiotic resistance in natural uropathogen isolates, which should strictly be avoided in treating UTIs that occur despite using sanitizers as preventive measures.

Keywords: Antibiogram, Toilet Seat Sanitizers, Uropathogens, Urinary Tract Infection

\section{INTRODUCTION}

Urinary tract infections (UTIs) are one of the most prevalent bacterial infections, with about 150 million reported cases worldwide, and an incurred economic loss of about 6 billion US dollars [1]. UTIs are more prevalent in women, mainly because of the anatomy of their urinary tract [2]. The prevalence of UTI in pregnant women worldwide is reported to range from 3$24 \%[3,4]$. In a study conducted in Meerut, India, it was seen that the highest prevalence of UTIs in women was seen in the age group of 26-36 years (90.69\%); however, in males, the highest susceptible age group to UTIs was $\geq 48$ years $(71.15 \%)$ [5]. This infection is also very common in children, with $3-8 \%$ of the cases occurring in girls, and $1 \%$ in boys, with an even greater risk for infants below the age of 6 months [6].

In the etiology of the UTIs, the most prominent pathogen worldwide is Escherichia coli [7]. While there have been many newly emerging uropathogens, the main UTI-causing ones are members of the family Enterobacteriaceae (Klebsiella, Enterobacter, Proteus), and species of the genera Pseudomonas, Vibrio, Staphylococcus, Enterococcus and Streptococcus [8].

Although there is a notion that bacteria are less likely to be found on cold hard surfaces such as toilet seats, research says otherwise [9]. Microbial aerosols created from flushing, improper cleaning of toilet seats after each use, and use of toilet by persons suffering from gastrointestinal diseases are some of the possible routes of addition of microbes to toilet seats [10]. A study to assess microbial flora present in public washrooms showed occurrence of a majority of bacteria such as E. coli, Pseudomonas spp., Staphylococcus spp., Vibrio spp., Streptococcus faecalis, and Acinetobacter spp. [10]. While many of these bacteria are uropathogenic, they have lesser chances of actually causing infections if proper washroom hygiene is maintained and toilet seats are cleaned regularly between each use [11]. However, in developing countries, such stringent practices cannot always be maintained due to socio-economic constraints, making the hygienic condition of public washrooms truly deplorable. This can lead to UTIs in users, especially in those with wound or compromised immunity [12]. 
Toilet seat sanitizers are a relatively new concept with regard to sanitation and public hygiene, which are being widely advertised, marketed and promoted nowadays. These sanitize and deodorize when sprayed instantly from a certain distance, and claim to kill 99.9\% uropathogens [13]. However, despite these huge claims, till date, no scientific studies have been conducted in any part of the world on the microbicidal efficacies of these sprays. Besides, increasing trends in antibiotic resistance among the common uropathogens is now a matter of great concern. A multi-centre study in Delhi, India, demonstrated extremely low susceptibility of the common uropathogens to some major first-line antibiotics like amoxicillin, amoxicillin / clavulanate, ciprofloxacin and co-trimoxazole [14]. According to a study conducted in Tamil Nadu, India, the occurrence of Extended spectrum beta-lactamase (ESBL) - producers in the urinary isolates of E.coli and Klebsiella pneumoniae was found to be $51.04 \%$ and $61 \%$ respectively [15, 16]. Hence, beta-lactam antibiotics were found to be ineffective against all of them $[15, \mathbf{1 6}]$. In another study performed in Aligarh, India, the common uropathogenic isolates were found to be resistant to ampicillin, chloramphenicol, erythromycin, rifampicin, sulphamathizole and tetracycline [17].

Hence, taking into consideration the above scenario, our present work is the first and unique of its kind to study the comparative microbiological profile of the toilet seats of ladies' public washrooms from three distinct sites in the city of Kolkata (a major railway terminal station, a tertiary care hospital and a shopping mall) before and after sprays with five different toilet seat sanitizers, to identify and confirm the presence of some common UTI-causing pathogens (E. coli - a fecal coliform, Pseudomonas spp., Vibrio spp. and Staphylococcus spp.) from the samples collected therefrom, and as a result, getting an idea of the relative antimicrobial efficacies of the toilet seat sanitizers against them. Also, to get a notion of the existence, nature and degree of the spread of multidrugresistance, antibiotic-susceptibility test of the uropathogen isolates was performed using some common, and some lesser-used antibiotics, and the respective antibiograms compared.

\section{MATERIALS AND METHODS}

Chemicals, reagents, dehydrated media, media base, supplements, antibiotics and toilet seat sanitizers

All chemicals and reagents used in this study were purchased from Merck Specialities 
Private Limited, India and Sisco Research Laboratories Private Limited, India. All dehydrated media, media base, supplements and the antibiotics (amoxicillin, doxycycline, azithromycin, vancomycin and ciprofloxacin) in the form of commercially-available impregnated discs (Table 1) were procured from HiMedia Laboratories Pvt. Ltd., India.

Five popular toilet seat sanitizers (II-VI) to be used in this investigative study, two of which (III and IV) are manufactured by Multinational Companies (MNC) and the other three (II, V and VI) by India-based companies, and of varying chemical compositions, were purchased from commercial outlets in the city of Kolkata,
India (Table 2). Cotton pads, $5.5 \mathrm{~cm}$ in diameter, were purchased from Dr. MorepenGubb (USA), New Delhi, India.

\section{Sample collection}

The study was conducted during summer, for over a period of two months (May-June 2019) in Kolkata, India. Toilet seat wash samples were collected from ladies' public washrooms from three different sites (sites 13) from three different geographical locations of the city, which are heavily thronged by common people all throughout the day - a major railway terminal station (site 1), a tertiary care hospital (site 2) and a shopping mall (site 3) (Table 3).

Table 1: Antibiotic discs and their concentration ( $\mu \mathrm{g} / \mathrm{disc})$

\begin{tabular}{|c|c|}
\hline ANTIBIOTIC DISC USED & CONCENTRATION $(\boldsymbol{\mu g} / \mathbf{d i s c})$ \\
\hline Amoxicillin & 30 \\
\hline Doxycycline & 30 \\
\hline Azithromycin & 15 \\
\hline Vancomycin & 30 \\
\hline Ciprofloxacin & 5 \\
\hline
\end{tabular}

Table 2: Toilet seat sanitizers, their chemical compositions and unit price (₹/ml)

\begin{tabular}{|c|c|c|c|}
\hline $\begin{array}{l}\text { TOILET SEAT } \\
\text { SANITIZER }\end{array}$ & CHEMICAL CONSTITUENTS & $\begin{array}{c}\text { PRICE } \\
\text { (₹/ml) }\end{array}$ & ORIGIN \\
\hline $\begin{array}{l}\text { II } \\
\text { III } \\
\text { IV } \\
\text { V } \\
\text { VI }\end{array}$ & $\begin{array}{c}\text { Eucalyptus globulus oil, Citronella oil, Water and Excipients } \\
\text { Isopropyl Alcohol, Benzalkonium Chloride, Fragrance, Solvents \& Propellant } \\
\text { Isopropyl Alcohol, Fragrance, Benzalkonium Chloride } \\
\text { Isopropyl Alcohol, Propellant, Fragrance, Tea-tree oil } \\
\text { Benzalkonium Chloride BP, Isopropyl Alcohol BP, Fragrance, Solvents \& } \\
\text { Propellant }\end{array}$ & $\begin{array}{l}1.98 \\
2.00 \\
2.40 \\
2.75 \\
2.00\end{array}$ & $\begin{array}{l}\text { India-based Company } \\
\text { Multinational Company } \\
\text { Multinational Company } \\
\text { India-based Company } \\
\text { India-based Company }\end{array}$ \\
\hline
\end{tabular}

Table 3: Sites of sample collection

\begin{tabular}{|c|c|c|c|}
\hline \multirow{2}{*}{ SITE NO. } & SITE & LOCATION IN KOLKATA & TIME OF COLLECTION \\
\hline & CITY & \\
1 & Major railway terminal station & North Kolkata & 10:00 A.M. - 11:00 A.M. \\
3 & Tertiary care hospital & Central Kolkata & 5:00 P.M - 6:00 P.M. \\
& Shopping mall & South Kolkata & 4:00 P.M. - 5:00 P.M. \\
\hline
\end{tabular}


Since UTIs are more prevalent in women and children, checking of the sanitation status of the toilet seats in the cubicles of the ladies' public washrooms, before and after sanitizer sprays, was the aim, as these are used not only by the ladies, but also much by the children accompanying them. From each of these three sites, six toilet seat wash samples were collected (samples I-VI), one control sample (I) collected before the application of the toilet seat sanitizer, and five experimental samples (II-VI) collected after the application of each of five different toilet seat sanitizers. Samples were collected between 10:00 A.M. and 11:00 A.M. from the railway station, between 5:00 P.M and 6:00 P.M. from the hospital, and between 4:00 P.M. and 5:00 P.M. from the shopping mall, which are their respective busiest hours. Each sample was collected under similar experimental conditions, as far as practicable. For collection of samples, $15 \mathrm{ml}$ of sterile $0.9 \%$ saline was taken in each sterile falcon tube. One sterile, round cotton pad was put in the saline solution in each of those falcon tubes, and the respective tubes taken to the sample collection sites. For all the three sites (sites 13), for each control sample (I), the cotton pad soaked in $0.9 \%$ saline was taken out from inside the respective falcon tube with a pair of sterile forceps, and slowly wiped over the surface of the toilet seat. The cotton pad was then put back inside the $0.9 \%$ saline in that particular falcon tube. For each of the five experimental samples (II-VI) to be collected from each site, each sanitizer was sprayed over the toilet seat from a $15 \mathrm{~cm}$ distance and allowed to act for 10 seconds (as per manufacturers' instructions on the sanitizer spray bottles), and the sample collected in the same way as for the control one. During sample collection, hands were covered with sterilized gloves so as to avoid any kind of contamination. After collection, all the sample-containing falcon tubes were placed in clean, dry, sterilized plastic containers, which were tightly sealed and transported to the laboratory for analysis. Prior to analysis, all the samples were refrigerated $\left(4^{0} \mathrm{C}\right)$.

\section{Sample preparation}

During analysis, each cotton pad was taken out of the respective falcon tube, and squeezed against the wall of another empty, sterile falcon tube, till all its contents came out. Each cotton pad yielded $2 \mathrm{ml}$ of the toilet seat wash sample. When each cotton pad was taken out of the first falcon tube, the residual $0.9 \%$ saline left behind was $12 \mathrm{ml} .2 \mathrm{ml}$ of each wash sample was then re-transferred to that $12 \mathrm{ml}$ of $0.9 \%$ saline in the first falcon tube, and mixed well. Each of these solutions 
is henceforth referred to as the sample-saline (1:7) mixture.

\section{Total heterotrophic count (THC)}

$1 \mathrm{ml}$ of each of the sample-saline mixtures, for each site and each sanitizer spray, was then used for the determination of total heterotrophic count (THC) in terms of $\log _{10} \mathrm{CFU}$ (colony forming units)/ml by standard Pour plate method, using nutrient agar (NA), and the plate incubated aerobically for 24 hours at $37^{\circ} \mathrm{C}$ [18]. Postincubation, the number of CFUs and colony morphologies in each plate were noted.

\section{Detection of uropathogens}

For the detection of the presence of the most important UTI-causing bacteria, E. coli, in each of the sample-saline mixtures, $3 \times 3$ Most Probable Number or MPN test was carried out using double strength (2X) and single strength (1X) lactose broth (LB), and the tubes incubated in a rotary shaker for 48 hours at $37^{\circ} \mathrm{C}[18,19]$. MPN index (number of coliform bacteria $/ 100 \mathrm{ml}$ ) was then determined through observation of bacterial growth and gas bubble formation in the tubes [20, 21]. For detection of other selected uropathogens like Pseudomonas spp. and Vibrio spp., $0.1 \mathrm{ml}$ of each sample-saline mixture was inoculated into $5 \mathrm{ml}$ of Cetrimide broth $(\mathrm{CB}$, primary enrichment medium for growth of Pseudomonas spp.) and $5 \mathrm{ml}$ of
Peptone water (PW, primary enrichment medium for growth of Vibrio spp.) [20]. All the test tubes were thereafter incubated in a rotary shaker for 48 hours at $37^{\circ} \mathrm{C}$, and observed for growth [20].

\section{Isolation of uropathogens}

To isolate the selected UTI-causing pathogenic bacteria (E. coli, Pseudomonas spp. and Vibrio spp.), a loopful of inoculum from each of the $2 \mathrm{X} \mathrm{LB}, \mathrm{CB}$ and $\mathrm{PW}$ tubes showing visible growth was streaked onto the selective media plates like Eosin Methylene Blue Agar (EMB), Pseudomonas Agar Base (PAB, with glycerol, C-F-C supplement and CetriNix supplement) and Thiosulphate Citrate Bile Salts Sucrose Agar (TCBS) respectively $[\mathbf{9 ,} \mathbf{2 0}]$. For the isolation of the uropathogenic Staphylococcus spp., a loopful of each sample-saline mixture was streaked onto the selective Baird Parker Agar (BP, with egg yolk tellurite emulsion supplement) plate $[9,20]$. All the plates were thereafter incubated aerobically for 24 hours at $37^{\circ} \mathrm{C}$, following which the growth of the uropathogens were noted, including the colony types and their morphological characteristics $[\mathbf{9}, \mathbf{2 0}]$. The typical colonies of the uropathogens isolated were subsequently sub-cultured twice on their respective selective media plates to purify and obtain pure cultures in the form of single, 
isolated colonies. The single colonies so obtained, with distinct characteristic features of the uropathogens (named as P1VId, T1 Vb, T1Vc, B ${ }^{1} 1 \mathrm{IIb}, \mathrm{B}^{1} 1 \mathrm{Vc}, \mathrm{E} 1 \mathrm{Ic}, \mathrm{E}^{1} 1 \mathrm{IIc}, \mathrm{E}^{2} 1 \mathrm{IIa}$, $\mathrm{E}^{2} 1 \mathrm{Vf}$ and $\mathrm{E}^{2} 1 \mathrm{VIg}$ ) were grown in NB tubes, and all the pure cultures refrigerated $\left(4^{0} \mathrm{C}\right)$ for further use.

\section{Confirmation of uropathogens}

The isolated pure culture of each of the selected uropathogens (E. coli, Pseudomonas spp., Vibrio spp. and Staphylococcus spp.) were confirmed by standard microbiological procedures including Gram-staining, and by a battery of characteristic biochemical tests including starch hydrolysis (SH), urea hydrolysis (UH) and gelatin hydrolysis (GH), nitrate reduction (NR), catalase production $(\mathrm{CP})$, oxidase production (OP), C-source (glucose, sucrose and fructose) utilization (growth in Triple Sugar Iron Agar, TSI), gas and $\mathrm{H}_{2} \mathrm{~S}$ production (in TSI agar), and response in Indole (I), Methyl Red (MR), Voges-Proskauer (VP) and Citrate Utilization tests (CUT) (IMViC) [21, 22]. Due to scarcity of time and infrastructural constraints, confirmation by ribotyping and serotyping could not be completed during the tenure of the study.

\section{Antibiotic susceptibility test}

Susceptibility test of the ten uropathogen isolates towards five antibiotics, some common, and some lesser-used, was performed according to the standard KirbyBauer Disc Diffusion Assay method, as per the recommendations of the Clinical and Laboratory Standards Institute (CLSI) [23, 24]. The commercially-available, different antibiotic-impregnated paper discs used in the study included amoxicillin (AMX, $30 \mu \mathrm{g} / \mathrm{disc}$ ), doxycycline (DO, 30 $\mathrm{g} / \mathrm{disc}$ ), azithromycin (AZM, 15 $\mu \mathrm{g} / \mathrm{disc}$ ), vancomycin (VA, 30 $\mathrm{g} / \mathrm{disc}$ ) and ciprofloxacin (CIP, $5 \mu \mathrm{g} /$ disc).

\section{Statistical analysis}

All results were expressed as mean \pm SEM (Standard Error of Mean) for an individual experiment. Each experiment was performed three times $(n=3)$, and the mean value from all the sets of those experiments presented [25]. Student's t-test was performed as applicable in each case, and the values were found to be significant at $5 \%$ probability level (P 0.05) [26].

\section{Computation, data analysis and graphics}

Windows Microsoft Word 2010 and Windows Microsoft Excel 2010 software were employed for all computation, data analysis and graphics. 


\section{RESULTS}

\section{Total heterotrophic count (THC)}

Colony morphologies (Figure 1) and the respective THC $\left(\log _{10} \mathrm{CFU} / \mathrm{ml}\right)$ (Table 4) were noted for each of the NA plates for each of the samples.

The respective percent reductions (Figure 2a, Table 4) were calculated from the corresponding THC values, and their mean values considered for representing the percent efficiency of each of the sanitizers (II-VI) in reducing microbial growth (Figure 2b, Table 4) [27].

Detection, isolation and confirmation of uropathogens

A similar, but not identical, trend in data was also seen for the MPN index (number of coliform bacteria $/ 100 \mathrm{ml}$ ). From the LB tube observations (Figure 3), a respective MPN index was assigned to each of the samples, according to the standard $3 \times 3$ MPN chart (Table 5).

The growth of the uropathogens from each of the control (I) and experimental samples (IIVI) from each site (1-3) were noted on the respective selective media plates (EMB, PAB, TCBS and BP), including their typical colony morphologies (Figure 4, Table 6).

The uropathogens were then confirmed by standard microbiological procedures including Gram staining (Table 6), and by some characteristic biochemical tests (Figure 5, Table 7).

\section{Antibiotic susceptibility test}

From the Kirby-Bauer Disc Diffusion Assay with the five antibiotics (Figure 6), the average diameter (in $\mathrm{mm}$ ) of the respective zones of growth inhibitionin case of each of the ten uropathogen isolates was calculated (Figure 7).

Based on the average diameter of their respective zones of inhibition for each of the five different antibiotics, using the Standard Kirby-Bauer Zone Size Data Interpretative Chart, the ten uropathogen isolates were classified as either resistant (R), intermediately susceptible (I) or completely susceptible (S) to each of the five antibiotics used (Figure 8) [28]. 

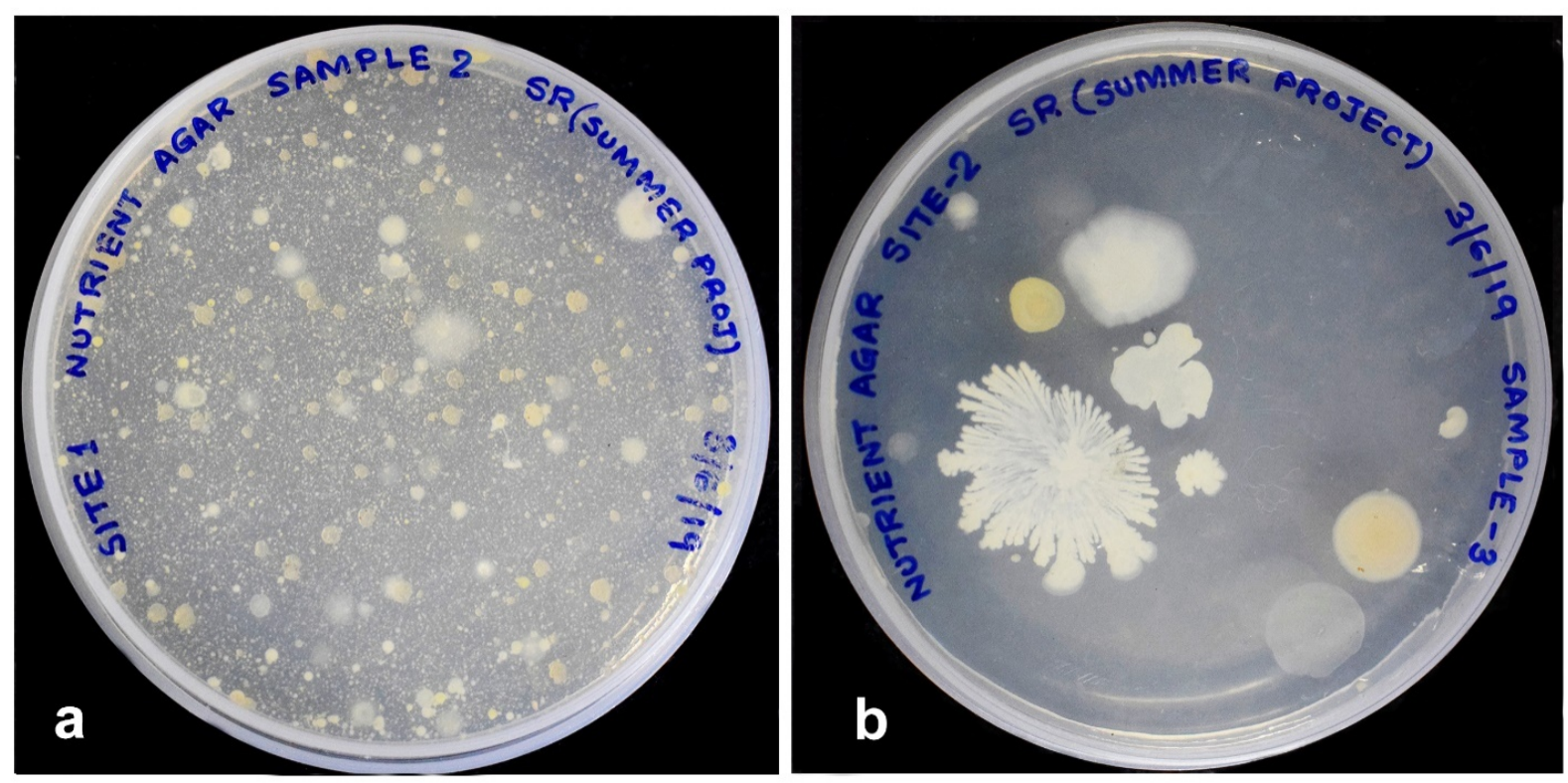

Figure 1: NA Plates showing the growth of various microorganisms from the plated samples: a: Site 1, Sample II; b: Site 2, Sample III

Table 4: Total Heterotrophic Count (THC, $\log _{10} \mathrm{CFU} / \mathrm{ml}$ ), $\log _{10}$ reduction in CFU/ml, percent reductions and mean percent efficiencies of the toilet seat sanitizers

\begin{tabular}{|c|c|c|c|c|c|c|}
\hline \multirow[b]{2}{*}{$\begin{array}{l}\text { TOILET SEAT } \\
\text { SANITIZER }\end{array}$} & \multirow[b]{2}{*}{$\begin{array}{l}\text { SITE } \\
\text { NO. }\end{array}$} & \multicolumn{2}{|c|}{ THC $\left(\log _{10} \mathrm{CFU} / \mathrm{ml}\right)$} & \multirow{2}{*}{$\begin{array}{c}\log _{10} \\
\text { REDUCTION IN } \\
\text { CFU/ml }\end{array}$} & \multirow{2}{*}{$\begin{array}{c}\text { PERCENT } \\
\text { REDUCTION } \\
(\%)\end{array}$} & \multirow{2}{*}{$\begin{array}{c}\text { MEAN PERCENT } \\
\text { EFFICIENCY } \\
(\%)\end{array}$} \\
\hline & & $\begin{array}{c}\text { BEFORE } \\
\text { SANITIZER } \\
\text { SPRAYING }\end{array}$ & $\begin{array}{c}\text { AFTER } \\
\text { SANITIZER } \\
\text { SPAYING } \\
\end{array}$ & & & \\
\hline II & $\begin{array}{l}1 \\
2 \\
3\end{array}$ & $\begin{array}{l}3.81 \\
3.77 \\
2.92\end{array}$ & $\begin{array}{l}3.51 \\
0.60 \\
0.30\end{array}$ & $\begin{array}{l}0.30 \\
3.17 \\
2.62\end{array}$ & $\begin{array}{l}49.88 \\
99.93 \\
99.76\end{array}$ & 83.16 \\
\hline III & $\begin{array}{l}1 \\
2 \\
3\end{array}$ & $\begin{array}{l}3.81 \\
3.77 \\
2.92 \\
\end{array}$ & $\begin{array}{l}1.71 \\
1.23 \\
0.48\end{array}$ & $\begin{array}{l}2.10 \\
2.54 \\
2.44\end{array}$ & $\begin{array}{l}99.21 \\
99.71 \\
99.64\end{array}$ & 99.52 \\
\hline IV & $\begin{array}{l}1 \\
2 \\
3\end{array}$ & $\begin{array}{l}3.81 \\
3.77 \\
2.92\end{array}$ & $\begin{array}{l}2.47 \\
1.04 \\
0.48\end{array}$ & $\begin{array}{l}1.34 \\
2.73 \\
2.44\end{array}$ & $\begin{array}{l}95.43 \\
99.81 \\
99.64\end{array}$ & 98.29 \\
\hline $\mathbf{V}$ & $\begin{array}{l}1 \\
2 \\
3\end{array}$ & $\begin{array}{l}3.81 \\
3.77 \\
2.92\end{array}$ & $\begin{array}{l}3.47 \\
1.60 \\
1.04\end{array}$ & $\begin{array}{l}0.34 \\
2.17 \\
1.88\end{array}$ & \begin{tabular}{|l|}
54.29 \\
99.32 \\
98.68
\end{tabular} & 84.02 \\
\hline VI & $\begin{array}{l}1 \\
2 \\
3\end{array}$ & $\begin{array}{l}3.81 \\
3.77 \\
2.92\end{array}$ & $\begin{array}{l}2.47 \\
0.77 \\
1.15\end{array}$ & $\begin{array}{c}1.34 \\
3.0 \\
1.77\end{array}$ & $\begin{array}{l}95.43 \\
99.90 \\
98.30\end{array}$ & 97.88 \\
\hline
\end{tabular}




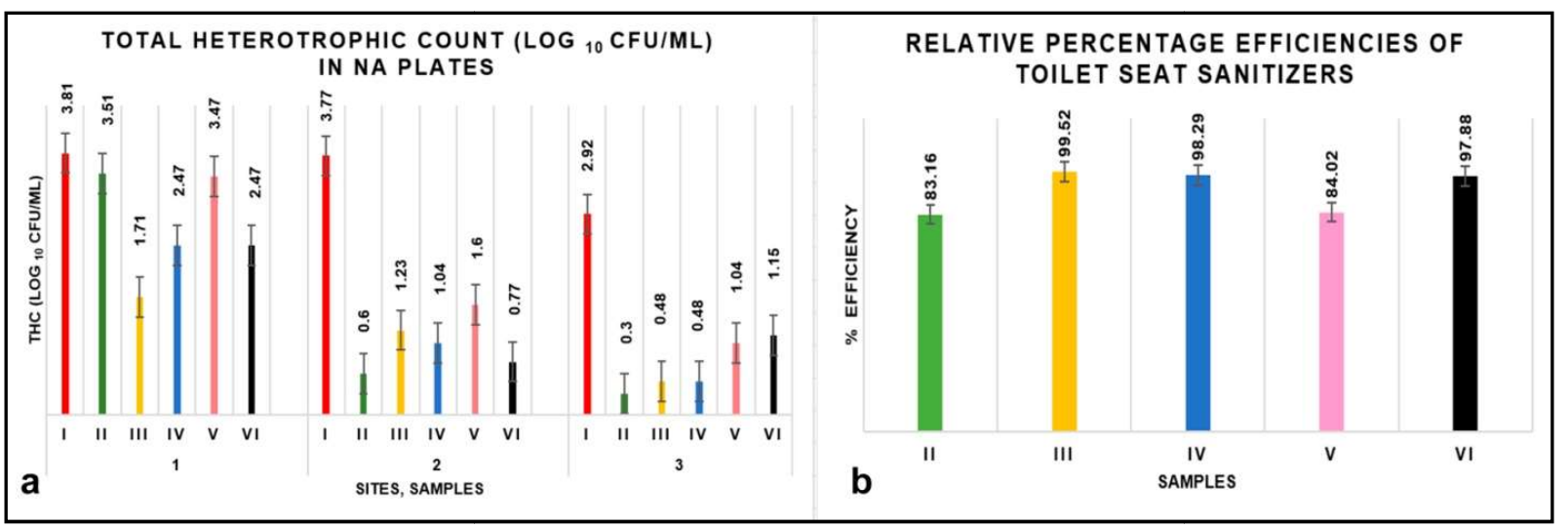

Figure 2: a: Graphical representations of relative THC $\left(\log _{10} \mathrm{CFU} / \mathrm{ml}\right)$ in the Control (I) and Experimental samples (II-VI) from 3 (1-3) sites of collection; b: Relative percent efficiencies of different toilet seat sanitizers (II-VI)

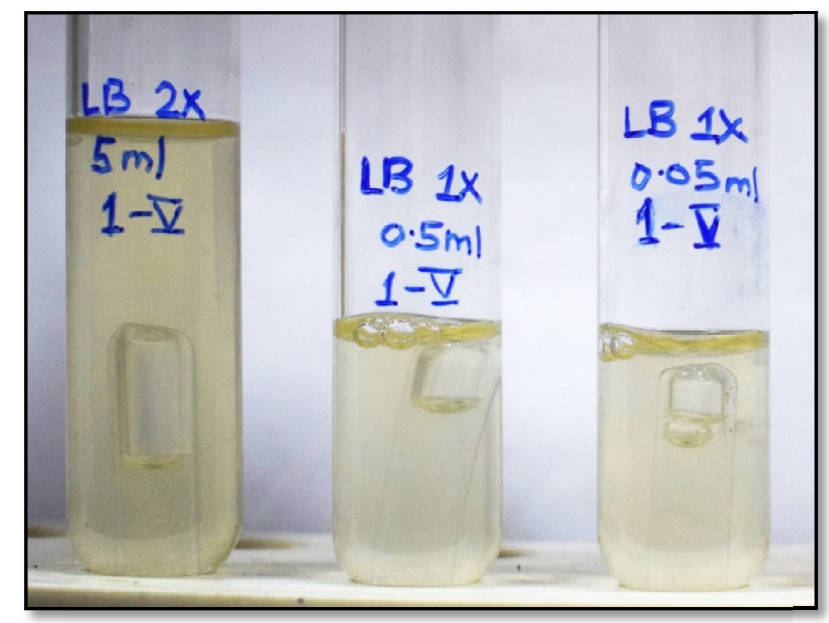

Figure 3: Representative result of $3 \times 3$ MPN test

Table 5: MPN Index (number of coliform bacteria/100ml) of Control (I) and Experimental samples (II-VI)

\begin{tabular}{|c|c|c|}
\hline SITE NO. & SAMPLE & MPN INDEX \\
\hline 1 & I & $>\mathbf{2 4 0 0}$ \\
& II & $>\mathbf{2 4 0 0}$ \\
III & 23 \\
IV & $<1$ \\
V & $>2400$ \\
VI & $>2400$ \\
\hline 2 & I & $>2400$ \\
& II & 240 \\
III & $<1$ \\
IV & 3 \\
V & 23 \\
VI & 23 \\
\hline 3 & I & 240 \\
& II & 23 \\
& III & 240 \\
& IV & $<1$ \\
& VI & 23 \\
& & $<1$ \\
\hline
\end{tabular}




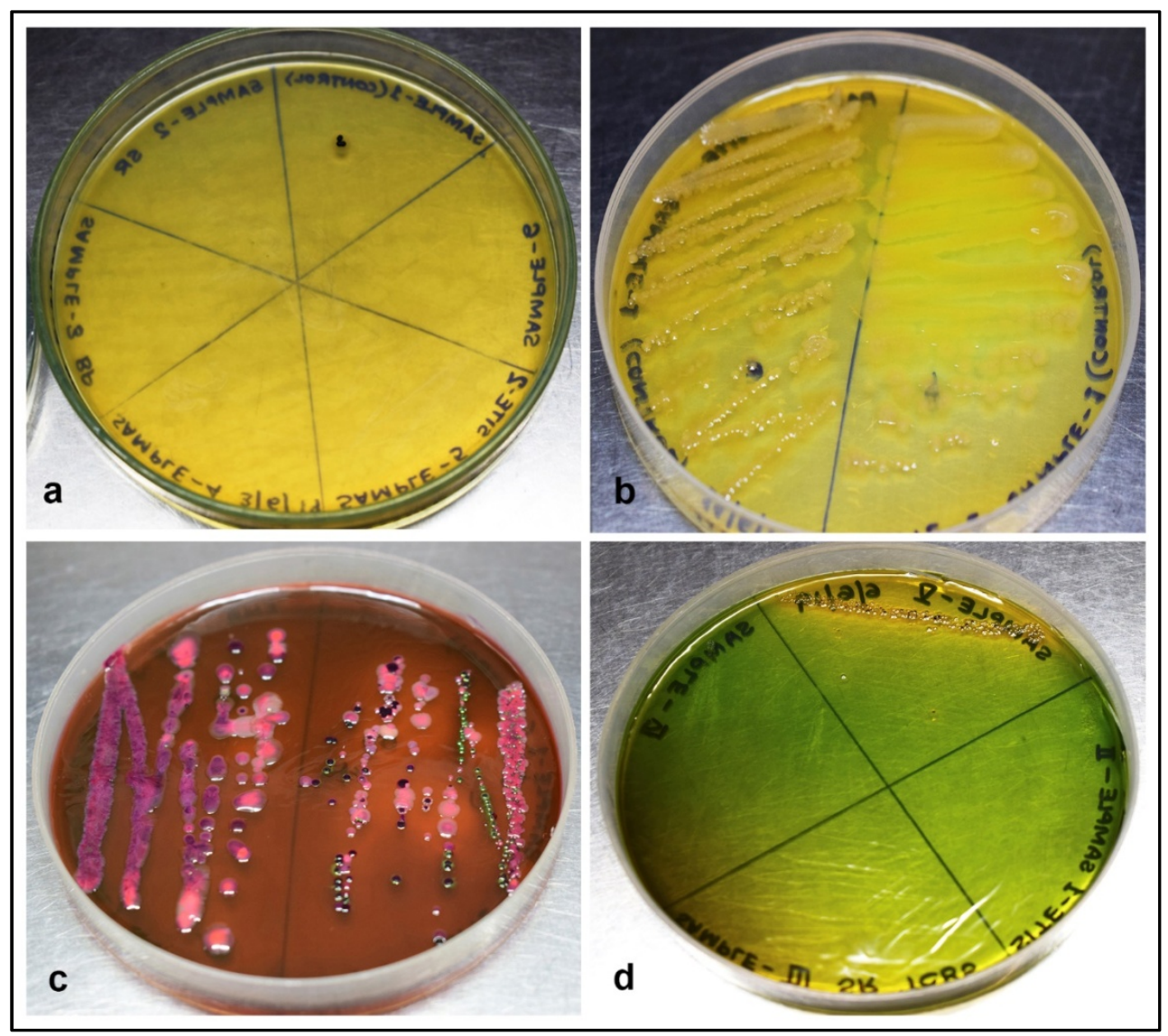

Figure 4: Representative selective media plates for different pathogens: a: BP plate showing growth of Staphylococcus spp. b: PAB plate showing growth of Pseudomonas spp. c: EMB plate showing growth of coliforms and non-coliforms d: TCBS plate showing growth of Vibrio spp.

Table 6: Characterization of the Uropathogens by Colony characteristics and Gram staining observations

\begin{tabular}{|c|c|c|}
\hline UROPATHOGEN & COLONY CHARACTERISTICS & GRAM STAINING OBSERVATIONS (400X) \\
\hline P1VId & Translucent colonies producing green pigment & Medium sized rod-shaped cells in single arrangement \\
\hline T1Vb & Yellow colonies, with dark black nucleation & Small comma shaped cells in single arrangement \\
\hline T1Vc & Yellow colonies & Small comma shaped cells in single arrangement \\
\hline B $^{1} 1 \mathrm{IIb}$ & Black colonies, slightly appressed & Small coccus shaped cells in cluster arrangement \\
\hline B $^{1} 1 \mathrm{Vc}$ & Grey colonies, raised in appearance & Small coccus shaped cells in cluster arrangement \\
\hline E1Ic & Translucent colonies producing a green sheen & Medium sized rod-shaped cells in single arrangement \\
\hline $\mathbf{E}^{1} 1 \mathrm{IIc}$ & Purple colonies, mucoid in nature & Medium sized rod-shaped cells in single arrangement \\
\hline $\mathbf{E}^{2} 1 \mathrm{IIa}$ & Pink colonies, mucoid in nature & Medium sized rod-shaped cells in single arrangement \\
\hline $\mathbf{E}^{2} 1 \mathrm{Vf}$ & Colorless colonies & Medium sized rod-shaped cells in single arrangement \\
\hline $\mathbf{E}^{2} 1 \mathrm{VIg}$ & Colorless colonies & Medium sized rod-shaped cells in single arrangement \\
\hline
\end{tabular}




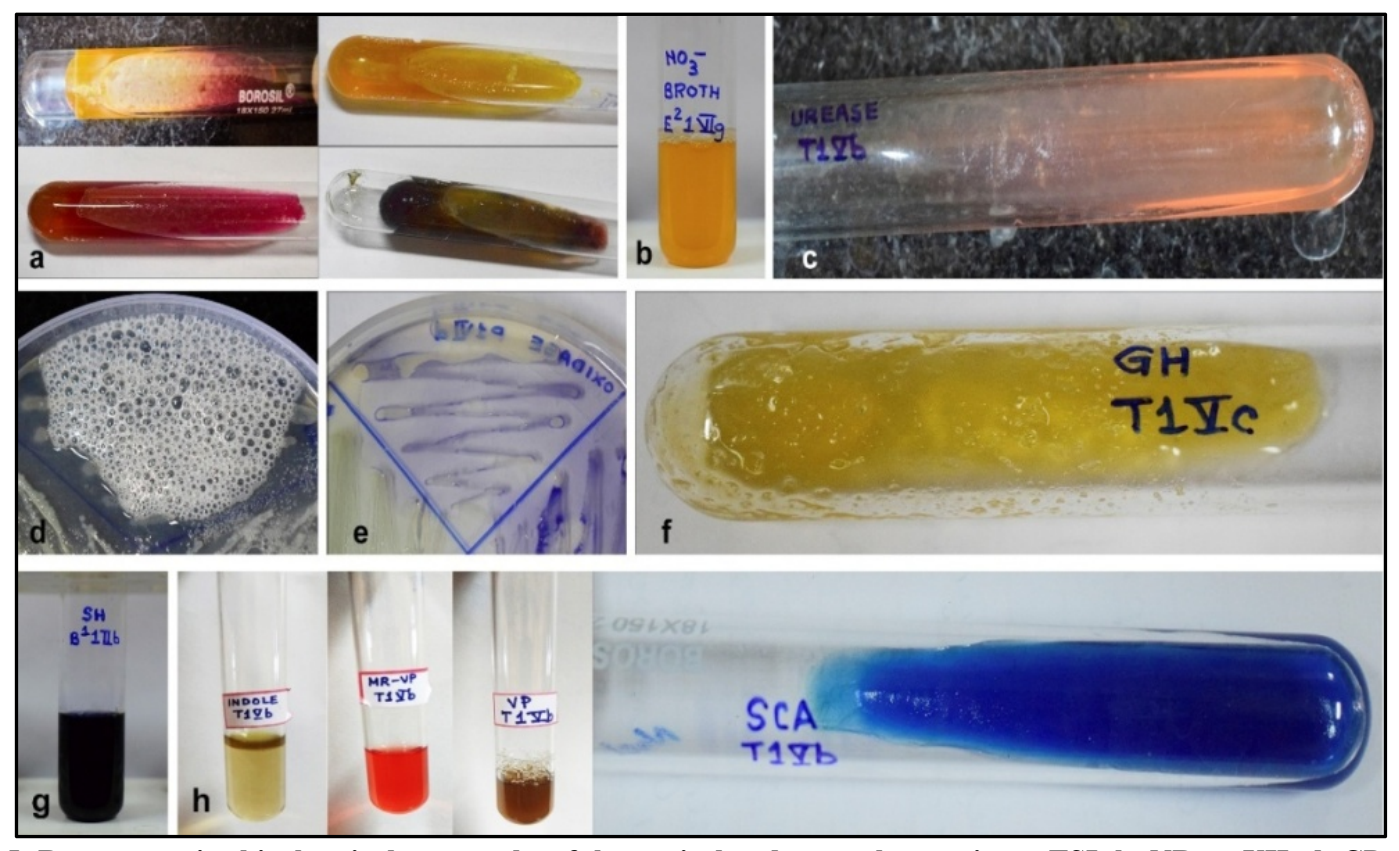

Figure 5: Representative biochemical test results of the ten isolated uropathogens in: a: TSI; b: NR; c: UH; d: CP; e: OP; f: GH; g: SH; h: IMViC

Table 7: Genus identification by Biochemical tests

\begin{tabular}{|c|c|c|c|c|c|c|c|c|c|c|c|c|c|c|}
\hline \multirow{2}{*}{$\begin{array}{c}\text { URO- } \\
\text { PATHOGEN }\end{array}$} & \multicolumn{3}{|c|}{ TSI SLANT } & \multirow[b]{2}{*}{ NR } & \multirow[b]{2}{*}{ UH } & \multirow[b]{2}{*}{$\mathbf{C P}$} & \multirow[b]{2}{*}{ OP } & \multirow[b]{2}{*}{ GH } & \multirow[b]{2}{*}{ SH } & \multicolumn{4}{|c|}{ IMVIC } & \multirow{2}{*}{$\begin{array}{c}\text { GENUS } \\
\text { IDENTIFIED }\end{array}$} \\
\hline & $\begin{array}{c}\text { SLANT/B } \\
\text { UTT }^{*}\end{array}$ & $\mathrm{H}_{2} \mathrm{~S}$ & GAS & & & & & & & I & MR & VP & CUT & \\
\hline P1VId & $\mathbf{K} / \mathbf{K}$ & Nil & Nil & + & Nil & + & + & + & Nil & Nil & Nil & Nil & + & Pseudomonas \\
\hline $\mathrm{T} 1 \mathrm{Vb}$ & K/A & + & + & + & + & + & Nil & + & Nil & Nil & + & Nil & + & Proteus \\
\hline T1Ve & K/A & Nil & Nil & + & Nil & + & + & + & + & + & Nil & Nil & Nil & Vibrio \\
\hline$B^{1} 1$ IIb & $\mathbf{A} / \mathbf{A}$ & Nil & Nil & + & + & + & Nil & + & Nil & Nil & Nil & + & + & Staphylococcus \\
\hline$B^{1} 1 V c$ & $\mathbf{A} / \mathbf{A}$ & Nil & Nil & + & + & + & Nil & + & Nil & Nil & + & + & Nil & Staphylococcus \\
\hline E1Ic & $\mathbf{A} / \mathbf{A}$ & Nil & + & + & Nil & + & Nil & Nil & Nil & + & + & Nil & Nil & Escherichia \\
\hline$E^{1} 1 I I c$ & $\mathbf{A} / \mathbf{A}$ & Nil & + & + & Nil & + & Nil & Nil & Nil & Nil & Nil & + & + & Enterobacter \\
\hline$E^{2} 1 I I a$ & $\mathbf{A} / \mathbf{A}$ & Nil & + & + & Nil & + & Nil & Nil & Nil & Nil & Nil & + & + & Enterobacter \\
\hline$E^{2} 1 V f$ & K/A & Nil & + & + & Nil & + & Nil & Nil & Nil & Nil & + & Nil & + & Salmonella \\
\hline$E^{2} 1 \mathrm{VIg}$ & K/A & Nil & + & + & Nil & + & Nil & Nil & Nil & Nil & + & Nil & + & Salmonella \\
\hline
\end{tabular}




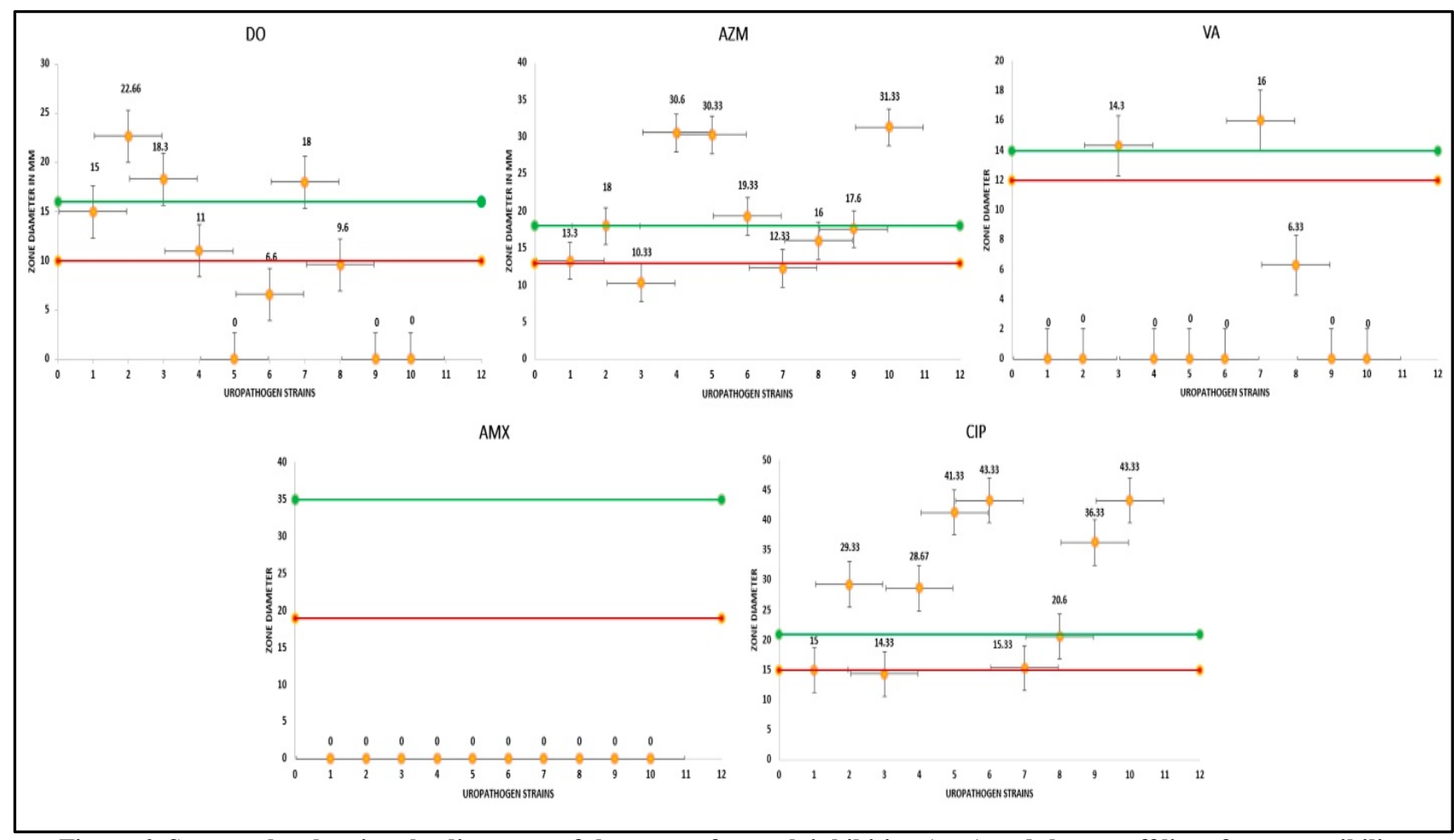

Figure 6: Scatter plot showing the diameters of the zones of growth inhibition (mm) and the cut-off lines for susceptibility (above the green line), intermediate susceptibility (between the green and red lines) and resistance (below the red line) of the ten isolated uropathogens towards the five antibiotics used; along X axis: 1 - E1Ic; 2 - $E^{2} 1 \mathrm{VIg} ; 3$ - B ${ }^{1} 1 \mathrm{IIb}^{2} 4$ - E ${ }^{1} 1$ IIc; 5 - T1Vb; 6 - P1VId; 7 - B 1 1Vc; 8 - T1Ve; 9 - E'1Vf; 10 -E 1 1Ia
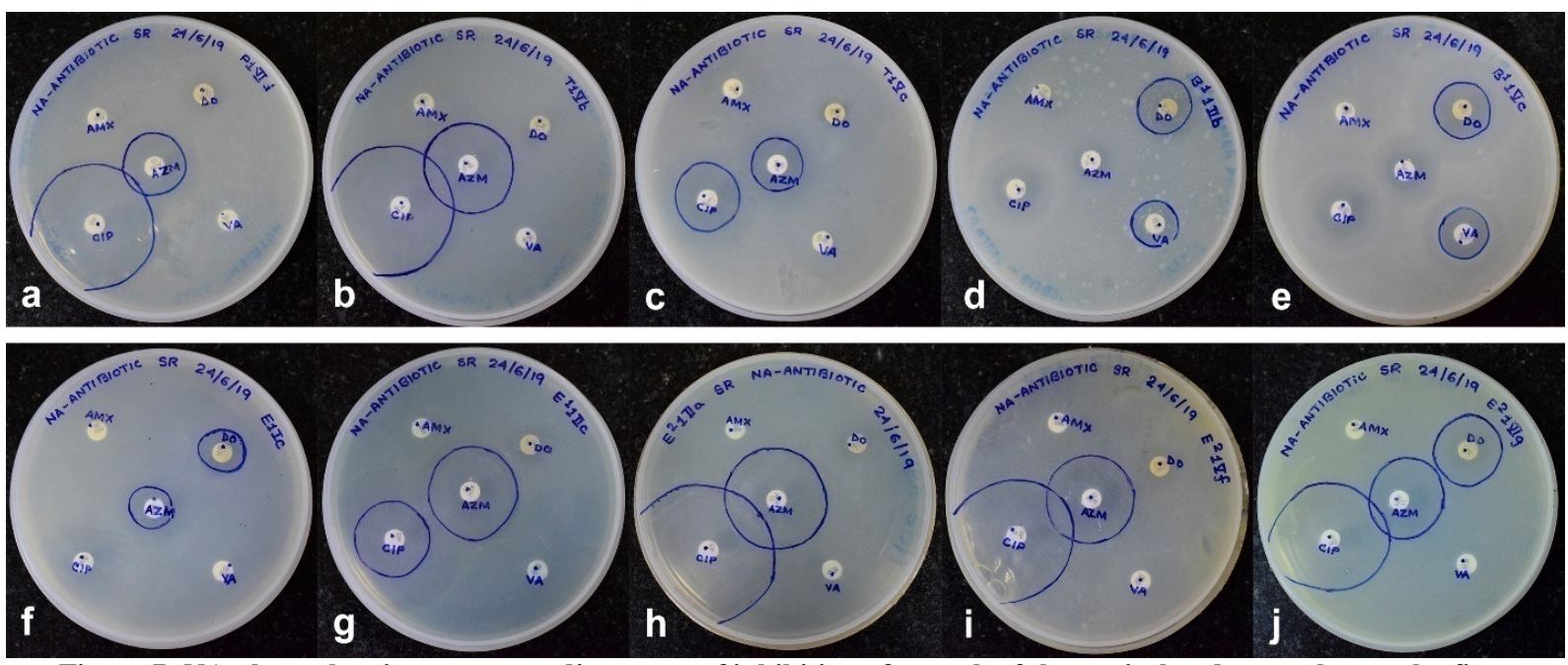

Figure 7: NA plates showing corresponding zones of inhibition of growth of the ten isolated uropathogens by five antibiotic discs: a: P1VId; b: T1Vb; c: T1Ve; d: $B^{1} 1 \mathrm{IIb}$; e: $B^{1} 1 \mathrm{Vc}$; f : E1Ic; g: $E^{1} 1 \mathrm{IIc}$; h: $\mathrm{E}^{2} 1 \mathrm{IIa}$; i: $E^{2} 1 \mathrm{Vf}$; j: $\mathrm{E}^{2} 1 \mathrm{VIg}$ 


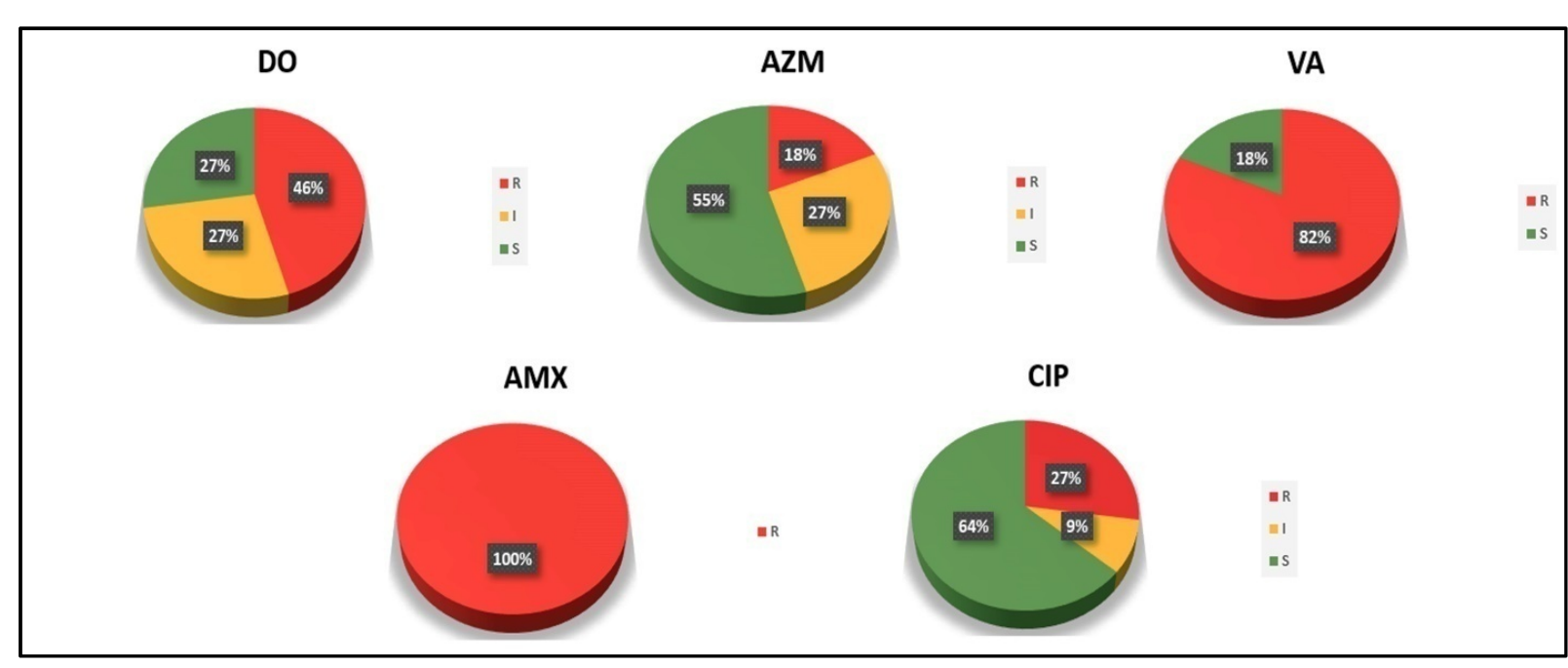

Figure 8: Pie charts showing the percentage (\%) of completely susceptible (S), intermediately susceptible (I) and resistant

\section{DISCUSSION}

(R) uropathogen isolates for the five antibiotics used

The control sample (I) collected from site 1 (ladies' public washroom in the major railway terminal station) recorded the highest THC $\left(\log _{10} \mathrm{CFU} / \mathrm{ml}\right)$ of 3.81 and a high MPN index (>2400), control sample (I) collected from site 2 (ladies' public washroom in the tertiary care hospital) showed an intermediate THC $\left(\log _{10} \mathrm{CFU} / \mathrm{ml}\right)$ of 3.77 and a high MPN index (>2400), whereas control sample (I) collected from site 3 (ladies' public washroom in the shopping mall) exhibited the least THC $\left(\log _{10} \mathrm{CFU} / \mathrm{ml}\right)$ of 2.92 and least MPN index (240) (Table 4, Table 5). This is quite logical considering that the ladies' public washroom in the major railway terminal station is frequented by a huge number of women (and children), with cleaning in between even a few uses being neither feasible nor practicable. In case of the shopping mall however, the washrooms are generally cleaned regularly between a few successive uses. Ladies' public washroom in the tertiary care hospital showed an intermediate THC value, denoting an average possible maintenance of hygiene. Keeping in mind that the aforesaid THC values also included most of the notorious uropathogens isolated in huge numbers, the above observations suggest that if proper hygiene is maintained within the public washrooms, and they are regularly washed, cleaned and disinfected at regular intervals, there will be much lesser chances of spread of UTIs among the users.

Reduced THCs (in all the 3 sites) (Table 4) and reduced MPN indices (particularly in site 2 and site 3) (Table 5) in case of the experimental samples II-VI, with respect to their respective controls (I), showed that the 
antimicrobial formulation of the toilet seat sanitizers helped in killing at least some of the uropathogens. The sanitizers were potent in reducing the growth of the uropathogens, but with varying efficiencies $(83.16 \%$ 99.52\%) (Figure 2, Table 4). However, none of them could kill $99.9 \%$ of the microorganisms, as claimed. The efficiency of sanitizer III in reducing microbial growth on the toilet seats was found to be closest to this claim, with the highest mean efficiency of $99.52 \%$, while sanitizer II turned out to be least potent with the least mean efficiency of $83.16 \%$ (Figure 2, Table 4). Based on their principal chemical constituents, it seems that sanitizers II and V, consisting of natural essential oils (Eucalyptus globulus oil and Tea-tree oil respectively) as the main ingredient, had the poorest performances with mean efficiencies of $83.16 \%$ and $84.02 \%$ respectively, whereas sanitizers III, IV and VI containing principal chemical components like benzalkonium chloride and isopropyl alcohol (which are widely used in disinfectants and sanitizers), showed more or less comparable efficiencies to each other (mean efficiencies of $99.52 \%, 98.29 \%$ and $97.88 \%$ respectively), while exhibiting relatively better performances than sanitizers II and V (Figure 2, Table 1, Table 4). Also, no linear correlation was found to exist between the price and effectiveness of the sanitizers. Sanitizer II, priced at 1.98 ₹ $/ \mathrm{ml}$ (least expensive) and sanitizer $\mathrm{V}$, priced at 2.75 ₹ $/ \mathrm{ml}$ (most expensive), both performed poorly (Figure 2, Table 1, Table 4).

Hence, this novel study, for the very first time, shows that the toilet seat sanitizers are a good measure of chemical control against the common uropathogenic bacteria, especially for the women commuters while travelling, as in our study conducted, all of them gave more-or-less satisfactory performances $(83.16 \%-99.52 \%)$ in killing most of the UTI-causing notorious pathogens. Sanitizers can thus be safely used to restrict the spread of UTIs contracted from soiled toilet seats of public washrooms. In future, further work that needs to be done is to go for altering and re-formulating the chemical composition of the toilet seat sanitizers, of those which are used in our study and some newer ones as well, and then determine their effectiveness against the same set or may be a new set of UTI-causing pathogens, so that the health care sector as well as the common public, particularly women, become aware of the use and potential efficacy of these sanitizer sprays in limiting the outbreak of this fatal disease in them.

CONCLUSION: UTIs often manifest fatal as the drug-resistant (DR) variety, and this 
complication is attributed to the involvement of multidrug-resistant (MDR) uropathogen strains as found in the form of natural isolates in this study. MDR bacteria are notorious, due to the major difficulties involved in excavating and applying the most suitable treatment regime for curing the fatal diseases they are associated with. The number and variety of antibiotic-resistant uropathogenic bacteria reported in this study is highly alarming, many of them being resistant to multiple antibiotics i.e. MDR [29, 30] (Figure 7). All the natural uropathogenic isolates obtained in this study were found to be resistant to AMX (Figure 7, Figure 8), which might be a consequence of doctors prescribing it for almost any common infection, including UTIs [31]. Resistances of the uropathogens to CIP and AZM were found to be comparatively lesser, excepting Escherichia coli and Staphylococcus spp. (Figure 7, Figure 8). Antibiograms for VA and DO showed that the corresponding uropathogen susceptibilities are intermediate, with every possibility of the drugs becoming ineffective very soon against the target microbes (Figure 7, Figure 8). In future, a periodic antibiogram profiling in every part of the world is thus required to formulate and re-design the necessary therapy for DR-UTIs. This makes the present study immensely significant clinically as it includes an indication of the antibiotic resistance patterns prevalent in natural uropathogen isolates, at least in this part of India, which can be used as reference information for treating both drug-sensitive (DS) - and DR-UTIs that can occur despite adoption of all possible precautionary measures, including the use of toilet seat sanitizers.

\section{ACKNOWLEDGEMENT}

The authors are deeply indebted to Rev. Dr. Dominic Savio, S.J., Principal and Rector, St. Xavier's College (Autonomous), Kolkata, and Mr. Agniv Basu, $5^{\text {th }}$ year M.Sc. student, Post-Graduate Department of Biotechnology, St. Xavier's College (Autonomous), Kolkata.

\section{REFERENCES}

[1] Gonzalez CM and Schaeffer AJ, Treatment of urinary tract infection: what's old, what's new, and what works, World JUrol, 1999; 17(6): 372.

[2] John AS, Mboto CI and Agbo B, A review on the prevalence and predisposing factors responsible for urinary tract infection among adults, Euro J Exp Bio, 2016;6(4):7.

[3] Le J, Briggs GG, McKeown A and Bustillo G, Urinary tract infections during pregnancy, Ann Pharmacother, 2004; 38(10): 1692. 
[4] Jayalakshmi J and Jayaram VS, Evaluation of various screening tests to detect asymptomatic bacteriuria in pregnant women, Indian J. Pathol. Microbiol, 2008; 51(3): 379.

[5] Prakash D and Saxena RS, Distribution and antimicrobial susceptibility pattern of bacterial pathogens causing urinary tract infection in urban community of Meerut city, India, ISRN Microbiol, 2013:749629 doi: 10. 1155/ 2013/ 749629: eCollection 2013.

[6] World Health Organization (WHO), Urinary tract infections in infants and children in developing countries in the context of IMCI, Geneva, 2005.

[7] Marrs CF, Zhang L and Foxman B, Escherichia coli mediated urinary tract infections: are there distinct uropathogenic $E$. coli (UPEC) pathotypes? FEMS Microbiol Lett, 2005; 252(2): 183.

[8] Sahu R, Sahoo RK, Prusty SK and Sahu PK, Urinary Tract Infection and its Management, Sys Rev Pharm, 2019; 10(1): 42.

[9] Howard BJ, Clinical and pathogenic microbiology, Mosby; 1994.

[10] Mendes MP and Lynch DJ, A bacteriological survey of washrooms and toilets, Epidemiol infect, 1976; 76(2): 183.

[11] Ohagim PI, Ikon GM, Matthew PC and Ohagim GA, Microbiological assessment of indoor air in public toilets across selected motor parks in Owerri Metropolis, Nigeria, $J$ Microbiol Exp, 2017; 5(6): 00166.

[12] Al-Badr A and Al-Shaikh G, Recurrent urinary tract infections management in women: a review, Sultan Qaboos Univ Med J, 2013; 13(3): 359.

[13] Rosscare Toilet Seat Sanitizer. https://www.rosscare.in/product/det ails/318. Accessed 16th March 2020.

[14] Kotwani A and Holloway K, Trends in antibiotic use among outpatients in New Delhi, India, BMC Infect Dis, 2011; 11(1): 99.

[15] Kulkarni DM, Bardapurkar SA, Nilekar SL and More SR, Prevalence of extended spectrum $\beta$ lactamase (ESBL) producing E. coli and Klebsiella species in urinary isolates, IOSR J Dent Med Sci, 2016; 15(6): 26

[16] Sankar S, Narayanan H, Kuppanan S and Nandagopal B, Frequency of extended-spectrum $\quad \beta$-lactamase 
(ESBL)-producing Gram-negative bacilli in a 200-bed multi-specialty hospital in Vellore district, Tamil Nadu, India, Infection, 2012; 40(4): 425 .

[17] Khan AU and Zaman MS, Multiple drug resistance pattern in urinary tract infection patients in Aligarh, Biomed Res, 2006; 17(3): 179.

[18] Cappuccino JG and Sherman N, Microbiology: A Laboratory Manual, $9^{\text {th }}$ Ed., Pearson, New York City, USA, 2005.

[19]United States Department of Agriculture, Food Safety and Inspection Service.

https://www.fsis.usda.gov/wps/wcm /connect/8872ec11-d6a3-4fcf 86df4d87e57780f5/MLG-Appendix2.pdf?MOD=AJPERES. Accessed 16th March 2020.

[20] Isenberg $H$, Clinical microbiology procedures handbook, Washington DC: American Society of Microbiology, USA, 1992.

[21] Murray PR, Baron EJ, Pfaller MA, Tenover FC, Yolken RH and Morgan DR, Manual of Clinical Microbiology, 6th Ed., ASM Press, 1995.
[22] Claus D, A standardized Gram staining procedure, World $J$ Microbiol Biotechnol, 1992; 8(4): 451.

[23] Bauer AW, Antibiotic susceptibility testing by a standardized single disc method, Am J Clin. Pathol, 1966; 45: 149.

[24] Biemer JJ, Antimicrobial susceptibility testing by the KirbyBauer disc diffusion method, Ann Clin Lab Sci, 1973; 3(2): 135.

[25] Jaykaran PY, Quality of reporting statistics in two Indian pharmacology journals, J Pharmacol Pharmacother, 2011; 2(2): 85.

[26] t Test, Educational Research Basics by Del Siegle.

https://researchbasics.education.uco nn.edu/t-test/\#. Accessed $16^{\text {th }}$ March 2020.

[27] Log and Percent Reductions in Microbiology and Antimicrobial Testing, Microchem Laboratory. https://microchemlab.com/informati on/log-and-percent-reductionsmicrobiology-and-antimicrobialtesting. Accessed $16^{\text {th }}$ March 2020.

[28] Antimicrobial Susceptibility Systems, HiMedia, Mumbai. http:// www.himedialabs.com/HML/image 
s/literature/pdf/100000027/68.pdf.

Accessed 16th March 2020.

[29] Saha S, Nayak S, Bhattacharyya I, Saha S, Mandal A, Chakraborty S, Bhattacharyya R, Chakraborty R, Franco OL, Mandal SM and Basak A, Understanding the patterns of antibiotic susceptibility of bacteria causing urinary tract infection in West Bengal, India, Front Microbiol, 2014; 5: 463.
[30] Ghosh A, Poddar S, Banerjee S, Choudhury J, Dhyay MM and Ray $\mathrm{J}$, Antibiotic Resistance in Community Acquired Urinary Tract Infection in Children: Data from a Tertiary Center in Eastern India, $J$ Clin Diagn Res, 2018; 12(1): 5.

[31] Akhavan BJ and Vijhani P, Amoxicillin, Treasure Island FL: StatPearls Publishing, USA, 2019. 